\title{
OP-0051 STRATIFICATION OF RISK OF DIABETES IN EARLY PREGNANCY (STRiDE) - PRELIMINARY RESULTS FROM THE KENYA COHORT
}

Priscah Osoro ${ }^{1}$ Sonak Pastakia ${ }^{2}$ Astrid Christoffersen-Deb ${ }^{4}$ Wycliffe Kosgei ${ }^{3}$ Beryl Ajwang' Onyango ${ }^{3}$ Joy Marsha ${ }^{1}$ Christabel Omukagah ${ }^{1}$ Catherine Amboka ${ }^{1}$ Caroline Kerich ${ }^{1}$ Benson Kiragu ${ }^{1}$ John Hector $^{1}$ Vincent Kibet ${ }^{1}$ Ponnusamy Saravanan ${ }^{5}$

${ }^{1}$ Academic Model Providing Access to Healthcare ${ }^{2}$ Purdue University College of Pharmacy ${ }^{3}$ Moi Teaching and Referral Hospital ${ }^{4}$ University of Toronto, Department of Obstetrics and Gynecology ${ }^{5}$ Warwick Medical School, University of Warwick

\section{BACKGROUND}

Data from high-income countries suggest women of certain ethnicities, including black Africans are considered at high risk of developing GDM.

* However, the overall risk of black African women living in LMICs and their risk factors for GDM is not known.

* Accurate prediction of GDM using HbA1c before the typical screening period of 24-32 weeks could aid in reducing the burden of testing and the maternal and fetal consequences of GDM.

\section{OBJECTIVES}

* To assess different ethnic specific risk factors for the development of GDM in Kenya.

* Testing the utility of additional biomarkers (such as $\mathrm{HbA1c}$ ) to facilitate the early prediction of GDM before 20 weeks.

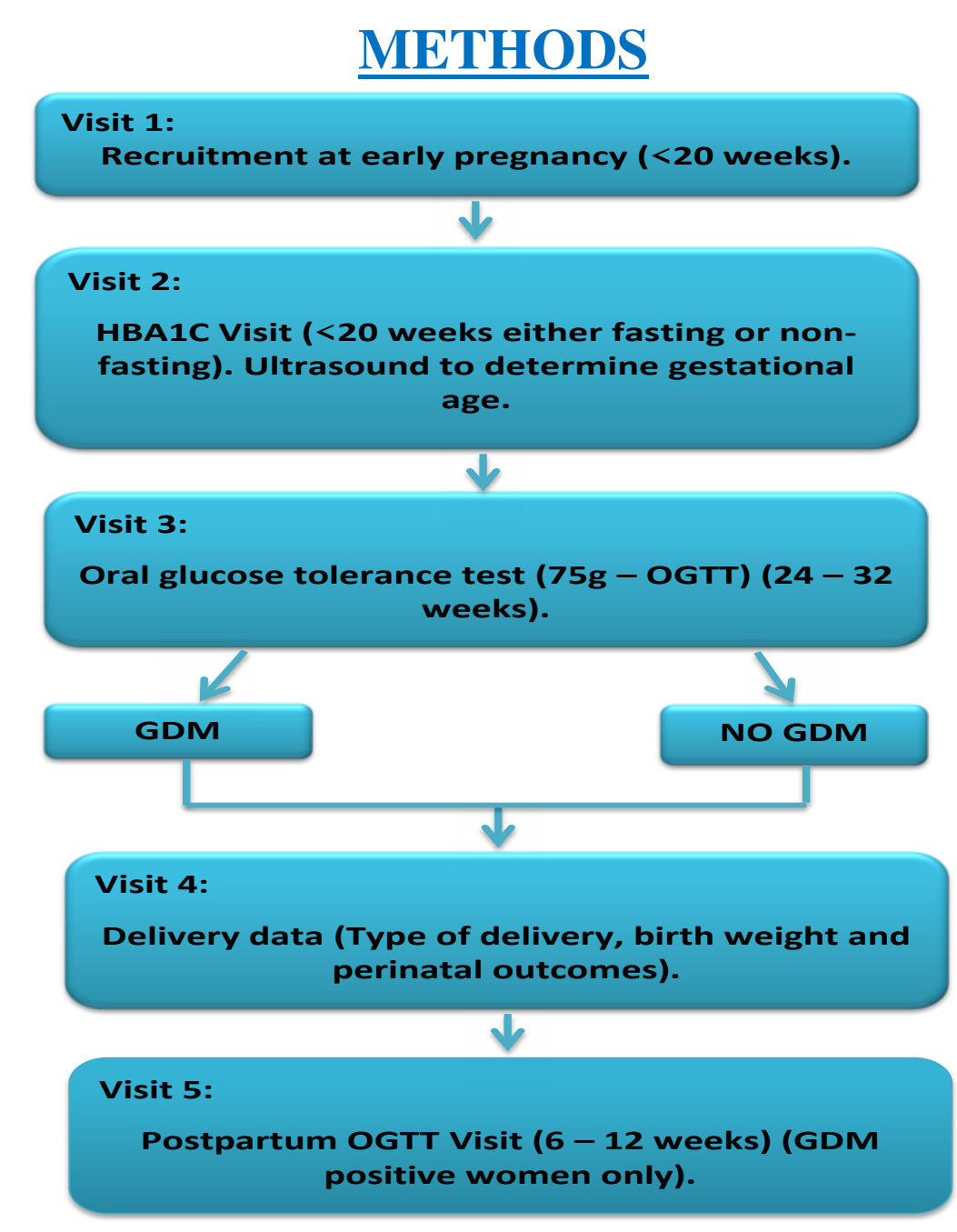

$\underline{\text { RESULTS }}$

Recruitment

2500

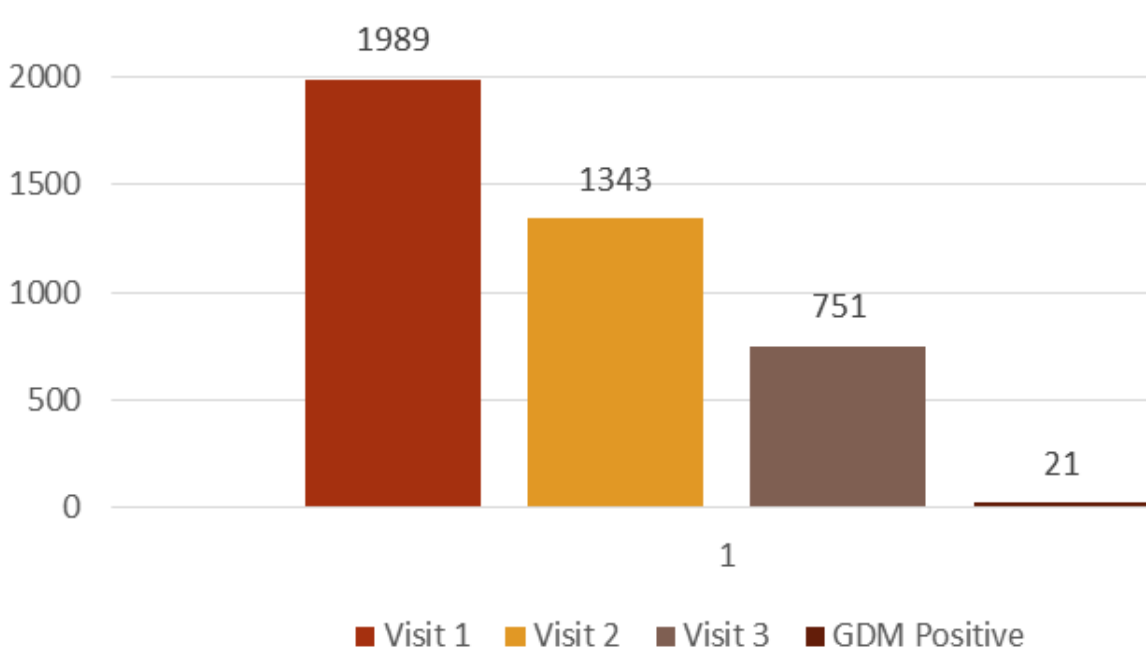

Figure 1: Progress of Enrollees Through the Study

\section{RESULTS CONTINUED}

\begin{tabular}{|c|c|}
\hline \multicolumn{2}{|r|}{ GDM Positive $\mathrm{N}=\mathbf{2 1}$} \\
\hline Age, n (\%) & \\
\hline$<35$ & $18(94.7)$ \\
\hline$>35$ & $1(5.3)$ \\
\hline Family history of GDM, n (\%) & \\
\hline Yes & $1(4.8)$ \\
\hline No & $20(95.2)$ \\
\hline Family history of Diabetes, n (\%) & \\
\hline Yes & $3(14.3)$ \\
\hline No & $18(85.7)$ \\
\hline BMI, n (\%) & \\
\hline$<25$ & $6(35.3)$ \\
\hline$>25$ & $11(64.7)$ \\
\hline $\begin{array}{l}\text { Obstetric risks } \\
\text { (miscarriage, still birth, neonatal } \\
\text { death), } n(\%)\end{array}$ & \\
\hline Yes & $4(25.0)$ \\
\hline No & $12(75.0)$ \\
\hline
\end{tabular}

Table 1: Characteristics of GDM positive mothers

\begin{tabular}{|c|c|c|c|c|}
\hline & $\begin{array}{l}\text { GDM } \\
\text { Positive }\end{array}$ & $\begin{array}{l}\text { GDM } \\
\text { Negative }\end{array}$ & Totals \\
\hline \multicolumn{2}{|c|}{ Visit $1 \mathrm{HbA} 1 \mathrm{C} \geq 6.0 \%$} & 4 & 31 & 35 \\
\hline \multicolumn{2}{|c|}{ Visit $1 \mathrm{HbA} 1 \mathrm{C}<6.0 \%$} & 17 & 596 & 613 \\
\hline \multicolumn{2}{|l|}{ Totals } & 21 & 627 & 648 \\
\hline & Specificity & Sensitivity & PPV & NPV \\
\hline $\begin{array}{l}\text { Visit } 1 \\
\mathrm{HbA} 1 \mathrm{C} \\
>6.0 \%\end{array}$ & $\begin{array}{l}596 / \\
(31+596) \\
=95 \%\end{array}$ & $\begin{array}{l}4 / \\
(17+4) \\
=19.0 \%\end{array}$ & $\begin{array}{l}4 / \\
(4+31) \\
=11.4 \%\end{array}$ & $\begin{array}{l}596 / \\
(596+17) \\
=97.2 \%\end{array}$ \\
\hline
\end{tabular}

Table 2: Diagnostic Accuracy of Early HbA1c Testing

\section{CONCLUSION}

Low prevalence rate of $3.2 \%$, highlighting the need for population specific screening strategies for GDM.

* In Kenya, the most significant risk factor for GDM is BMI as opposed to age, past obstetric outcomes and family history of diabetes and/or GDM.

* Early pregnancy HbA1c could be used for risk prediction for GDM.
PRISCAH OSORO onkwarepriscah@ gmail.com STRIDE Study

Moi Teaching and Referral Hospital

Eldoret, Kenya 30100 